\title{
Management of gallbladder empyema in a patient with situs inversus, levocardia and morbid obesity: a case report
}

Dulcyane Ferreira de Oliveira 1, Denis Alves Pinho 2, Fernando Fernandes Rodrigues 2, *, Luiz Fabrício Moura Marques 2, Pedro Henrique Rosa Araújo 2, Reginaldo Conrado Pinheiro 2, Yomara Jesuina Lins Rodrigues 2

${ }^{1}$ Serviço de Cirurgia Geral, Instituto de Cirurgia do Estado do Amazonas (ICEA), Amazonas, AM, Brazil.

2 Departamento de Medicina, Fametro University Center, Amazônia, AM, Brazil.

* Corresponding author: Fernando Fernandes Rodrigues. Parque dos Franceses, n⿳9060-Dom Pedro. Zip Code: 69050-045-Amazonas, AM, Brazil. Phone: +55(93) 99191-6241. E-mail: fernandesfernando292@yahoo.com.

Research Ethics Committee Approval (if necessary): We declare that the patient approved the study by signing an informed consent form and the study followed the ethical guidelines established by the Declaration of Helsinki.

Received on: Jul 19, 2021. Accepted on: Aug 25, 2021. Available online: Aug 30, 2021.

\begin{abstract}
Situs Inversus with levocardia is an unusual condition, in which the main organs of the thorax and abdomen are located in a reverse or enantiomorphic position in relation to the usual topography. It is estimated a prevalence of 1:10000 people with some Situs Inversus condition, but Situs Inversus with Levocardia is reported in only 1:22000 cases. The presence of acute cholecystitis in patients is an extremely rare event,however, one of its possible complications, Gallbladder Empyema can develop, causing an increase in severity and the need for surgical intervention. Since the inversion of abdominal organs proper to Situs Inversus with levocardia is commonly associated with the transposition of great vessels, fatally, as described in the literature of Vesicle empyema and Situs Inversus, it only occurred in patients with dextrocardia, not yet being reported in patients with Levocardia. We report a case of a female patient with pain in the left hypochondrium with Situs Inversus Viscerum, Levocardia, Empyema of Biliary Vesicles and Morbid Obesity.
\end{abstract}

Keywords: Situs Inversus; Gallbladder Empyema; Cholecystitis.

\section{Introduction}

Situs Inversus is a mirror image condition of the abdominal organs, determined by a rare genetic disorder characterized by an autosomal recessive congenital variation, with equal 
involvement between the sexes. There is no predominance between races and its incidence is not well established, but it is estimated a prevalence of 1:10000 people with some Situs Inversus condition, while Situs Inversus with Levocardia is reported in only 1:22000 cases [1].

The situation of Situs Inversus with Dextrocardia usually goes unnoticed, while Situs Inversus with Levocardia is usually associated with cardiac malformations, such as transposition of large vessels, with high lethality rates, and this condition is mainly found in autopsies of patients who died at an early age. In other cases, it is commonly associated with the presence of asplenia or polysplenia, with a survival rate of 5 to $13 \%$ in 5 years [2].

The following case is a woman, with morbid obesity, diabetes mellitus and arterial hypertension, who presented to the surgical emergency department with abdominal pain and sepsis associated with Gallbladder Empyema, being discovered during hospitalization the condition of Situs Inversus Viscerum and Levocardia. This clinical condition is a surgical challenge with a need for immediate intervention [3].

\section{Case report}

Primarily, we declare that the patient approved the study by signing an informed consent form and the study followed the ethical guidelines established by the Declaration of Helsinki. A 46 years old woman patient, diabetic, hypertensive and morbidly obese (Body Mass Index- $66 \mathrm{~kg} / \mathrm{m}^{2}$ ), was admitted to the Hospital complaining episodes of epigastric colic pain, radiating to the left dorsum and right iliac fossa for about 06 months, associated with copious eating, worsening in the last 48 hours, when associated with nausea, vomiting and increased intensity.

She denied coluria or fecal acolia. She underwent an abdominal ultrasound that revealed only "Cholelithiasis" and was discharged from the hospital after a brief improvement after medication. With the return and even worsening of symptoms in two days, she sought the surgery service, reporting abdominal pain and fever.

On physical examination, she had scleral jaundice, but mucocutaneous pallor. Respiratory and cardiac system unchanged. Abdomen: apron, normotensive, with a palpable mass on the left due to the plastron, sign of "Curvosier-Terrier" and "Murphy" present on the Left. She performed 
Magnetic Nuclear Resonance which intense inflammatory change and revealed Situs Inversus, characterized adjacent liquid laminae and by the inversion of the liver, spleen and perivesicular collection measuring stomach. In addition to a gallbladder approximately $4.9 \times 4,4 \times 4.0 \mathrm{~cm}$ with diffuse parietal thickening, (45.0cc). Hepatocoledocal duct with an multiple low-signal calculi on T2 inside, measuring 0.2 to $1.5 \mathrm{~cm}$, associated with approximate caliber of $0.3 \mathrm{~cm}$, without calculi inside (Figure 01 and 02).

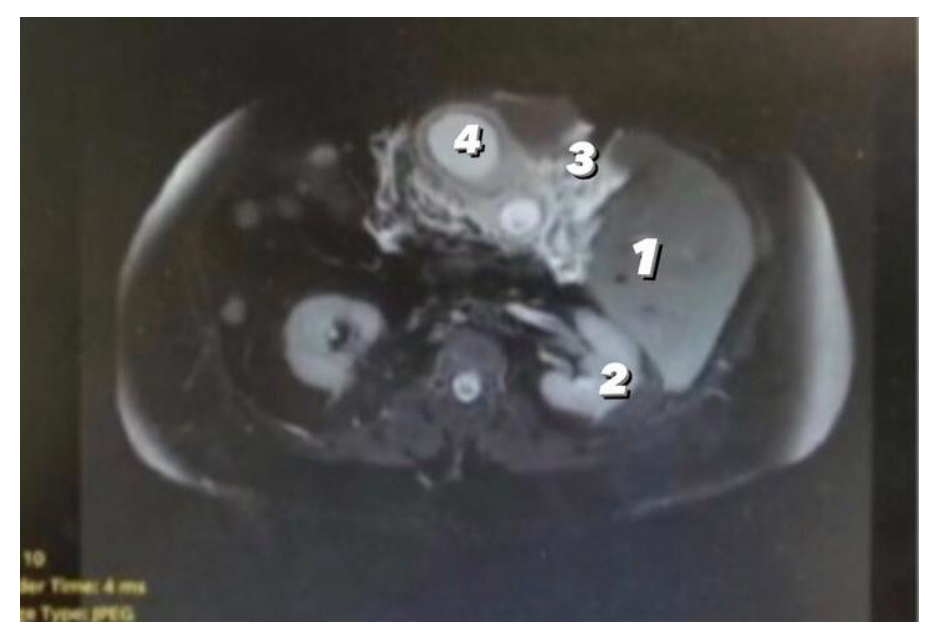

Figure 1. Cross Section. 1. Liver. 2. Kidneys. 3. Gall Bladder. 4. Stomach.

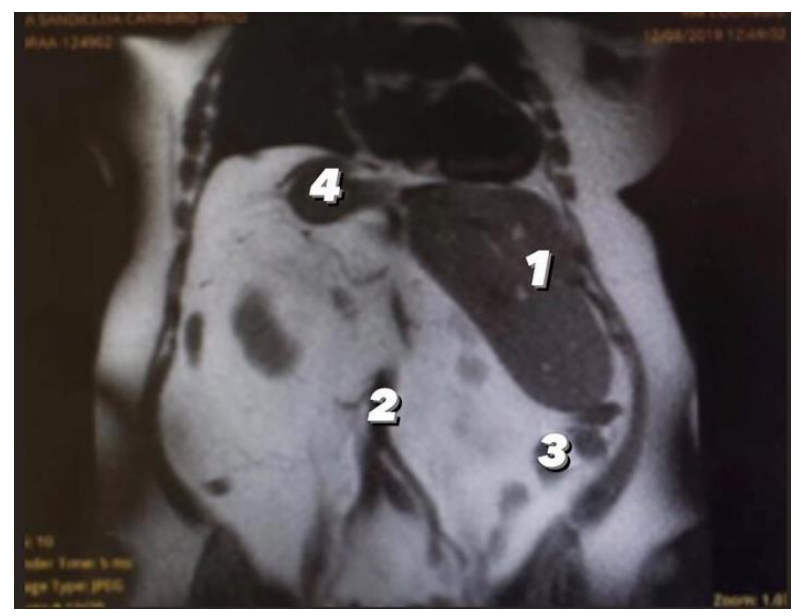

Figure 2. Sagittal Section. 1. Liver. 2. Small Intestine. 3. Aorta and Iliac vessels. 4. Stomach. Inversion of the liver and stomach.

Laboratory tests, however, with conventional (open) revealed septic status, indicating the cholecystectomy being performed with need for an urgent surgical approach, an enlarged and inverted Mercedes 
incision - in which an oblique incision is made to the left, following the costal margin, with the surgical team in an atypical position, with the main surgeon on the patient's left.

The cavity inventory showed the presence of a large plastron of eplon and loops, the presence of an accessory spleen and confirmation of the situation of Situs Inversus, with liver and gallbladder positioned in the left hemiabdomen. The gallbladder was turgid, with wall necrosis, empyema and multiple soft yellow stones inside (Figure 3).

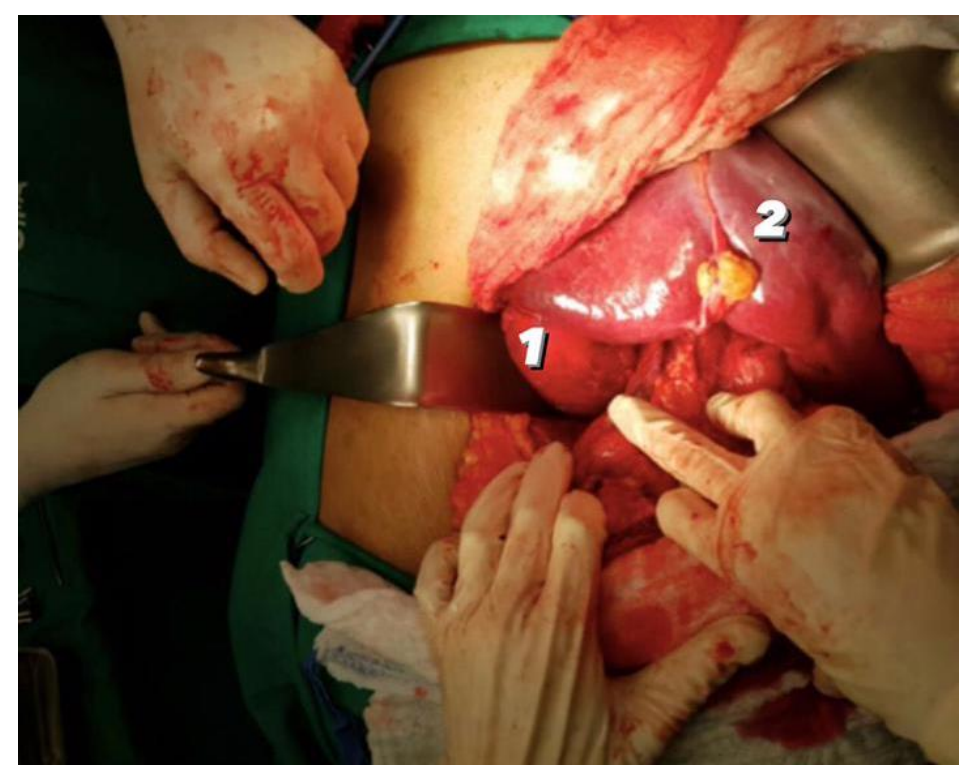

Figure 3. 1. Gallbladder. 2. Liver. Anatomical relationship in a patient with Situs Inversus, with Liver and Gall Bladder (GB) positioned in the left hypochondrium.

Once the surgical drainage of the gallbladder empyema was performed to facilitate access to the triangle of Calot, the cystic duct and cystic artery were ligated with removal of the specimen from the hepatic bed at Torek, due to an intense inflammatory process, followed by exhaustive washing with saline solution and cavity drainage (Figure 4 and 5). The patient had a favorable evolution, in treatment and received medical discharge. 


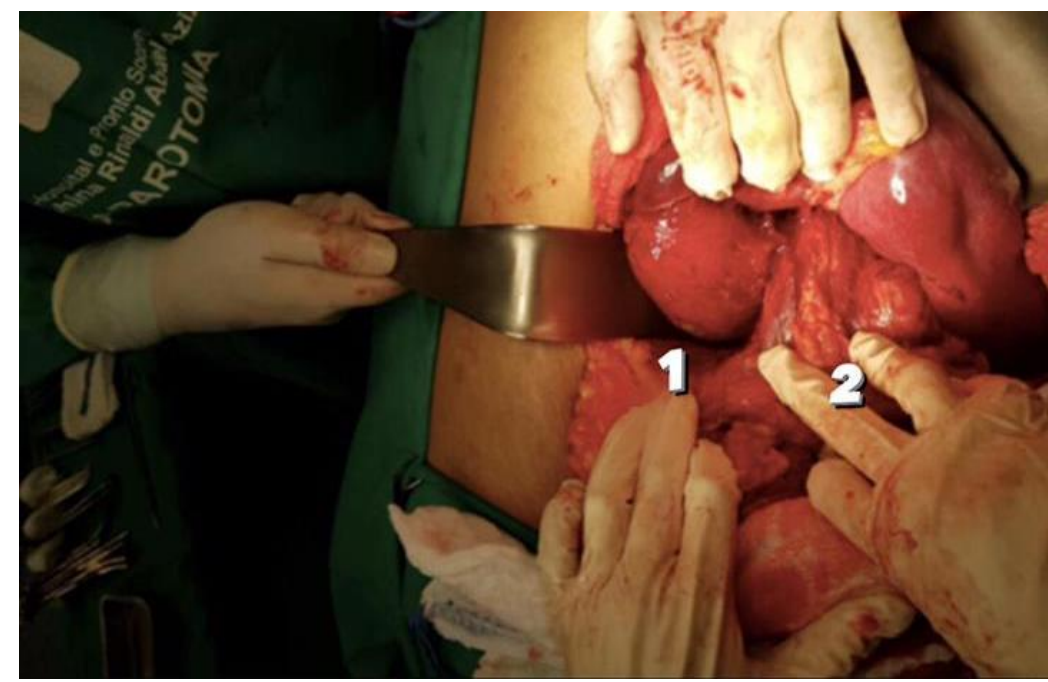

Figure 4. 1. Gallbladder. 2. Plastron. Gallbladder turgid, with areas of wall necrosis (Arrow), and presence of a plastron formed by an epiplon.

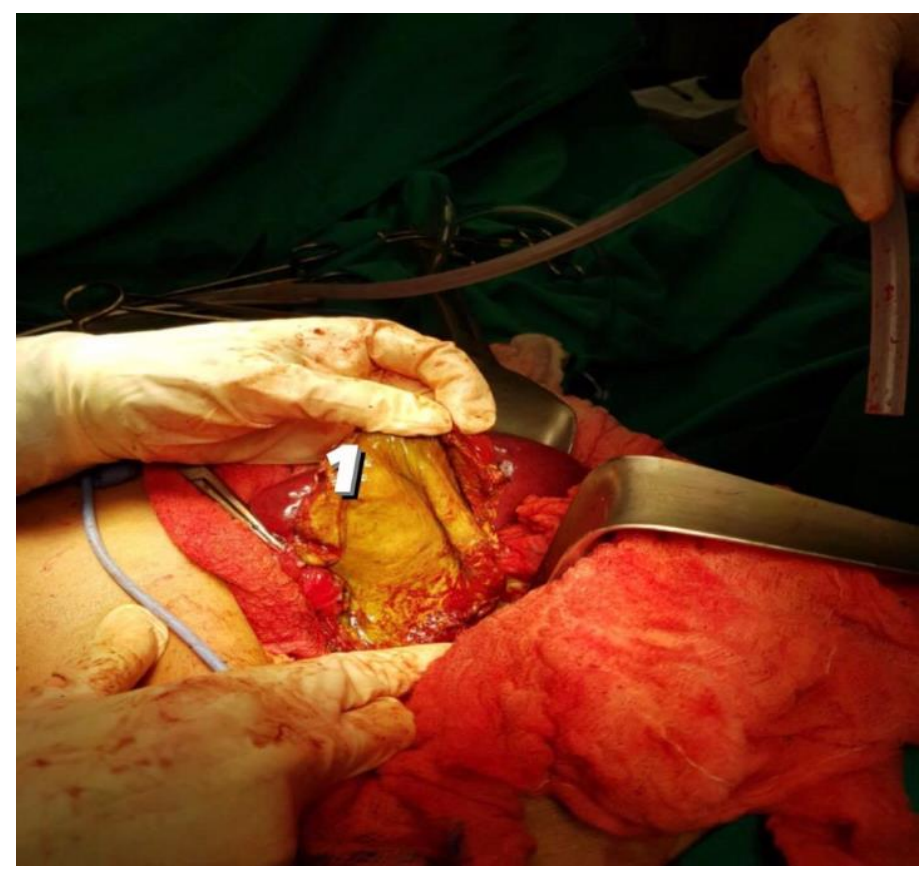

Figure 5. 1. Thick Gallbladder wall. Gallbladder dissection from the liver bed at Torek, with a thickened gallbladder wall being visualized.

\section{Discussion and Conclusion}

The case report presented refers to a conventional (open) cholecystectomy

procedure, complicated by atypical intrinsic factors such as situs viscerum inversus, levocardia and gallbladder empyema 
due to cholelithiasis, in addition to morbid obesity, presenting itself as a challenge surgical, in which immediate intervention is urgently needed [4].

Acute cholecystitis in patients with situs inversus viscerum is a rare event [5]. According to the besto $f$ our knowledge, only two cases of a patient with situs viscerum inversus with gallbladder empyema have been published to date. In these cases, the surgical procedure was performed laparoscopically in patients with situs inversus associated with dextrocardia, differing from our report in which the patient had the heart in the usual topography and the inversion occurred only in relation to the abdominal viscera, which led to a diagnostic challenge [5].

Situs Inversus with Levocardia is a rare condition with high lethality associated with cardiac malformation. The surgical procedure most commonly performed in these patients is related to transposition of great vessels, a consequence of the inverse topography of Organs abdominal organs in relation to the heart. However, the most common cause of cholecystectomy in patients with situs inversus is chronic cholecystitis due to cholelithiasis [6-7].

Cholecystectomy can be performed openly or laparoscopically. As the patient was morbidly obese, there would be benefits from performing laparoscopic surgery, however, as the hospital does not have this service, it was decided to perform conventional (open) surgery, given the emergency and the need not to delay the surgical procedure. The procedure was performed with the team's mirrored position in relation to the usual open surgery, that is, with the surgeon positioned to the patient's left. With the Mercedes incision for allowing great access to the upper abdômen [8].

When this procedure occurs by laparoscopy, the surgeon may choose to position himself on the patient's right the most suitable position, or between the patient's abducted lower limbs with the 1st assistant on the right and the second on the left [9].

Closing a clinical diagnosis in patients with cholelithiasis and situs inversus viscerum can be difficult to conclude since the signs and symptoms atypically manifest as pain in the left hypochondrium, epigastrium or scapular area due to incomplete transposition of visceral nerves, too, to nausea and vomiting. Imaging tests, usually ultrasound or tomography of the abdomen, should help and prevent misdiagnosis [8-9].

\section{References}

[1] Walker C, Hankin M, Nelsen S. An Unusual Case of Levocardia with Situs Inversus.

FASEB

Journal. 
2019;33:616.22.616.22. doi: 10.1096 / fasebj.2019.33.1_supplement.616.22.

[2] Venu RP, Geenen JE, Hogan WJ, Johnson GK, Taylor AJ, Stewart ET, Jackson A. ERCP and endoscopic sphincterotomy in patients with situs inversus. Gastrointest Endosc. 1985 Oct;31(5):338-40. doi: 10.1016/s00165107(85)72220-1.

[3] Watanabe M, Ueki K, Okinaga $\mathrm{Y}$, Umekawa $Y$, Hidaka M, Hirakawa $H$, Fukumoto S, Shimada Y. Laparoscopy of situs inversus totalis. Endoscopy. 1989 Nov;21(6):293-4. doi: 10.1055/s2007-1010725.

[4] Žatecký J, Hájek J, Ihnát P. Laparoscopic cholecystectomy in patient with situs viscerum inversus totalis and gallbladder empyema - a case report. Rozhl Chir. 2018 Summer;97(10):469472 .

[5] Goh P, Tekant Y, Shang NS, Ngoi SS. Laparoscopic cholecystectomy in a patient with empyema of the gallbladder and situs inversus. Endoscopy. 1992 Nov;24(9):799-800. doi: 10.1055/s-2007-1010589.

[6] Salama IA, Abdullah MH, Houseni M. Laparoscopic cholecystectomy in situs inversus totalis: Feasibility and review of literature. Int J Surg Case Rep. 2013;4(8):711-5. doi: 10.1016/ j.ijscr.2013.02.030.
[7] Lochman P, Hoffmann P, Kočí J. Elective laparoscopic cholecystectomy in a 75-year-old woman with situs viscerum inversus totalis. Wideochir Inne Tech Maloinwazyjne. 2012 Aug;7(3):216-9. doi: 10.5114/ wiitm.2011.26842.

[8] Kumar S, Fusai G. Laparoscopic cholecystectomy in situs inversus totalis with left-sided gall bladder. Ann R Coll Surg Engl. 2007 Mar;89(2):W16-8. doi: 10.1308/147870807X160461.

[9] Iusco DR, Sacco S, Ismail I, Bonomi S, Virzì S. Three-trocar laparoscopic cholecystectomy in patient with situs viscerum inversus totalis: case report and review of the literature. G Chir. 2012 Jan-Feb;33(1-2):10-3.

Conflict of interest: The author declares no conflicts of interest.

\section{Acknowledgements: None.}

\section{Funding: None.}

How to cite this article: Oliveira DF, Pinho DA, Rodrigues FF, Marques LFM, Araújo PHR, Pinheiro RC, Rodrigues YJL. Management of Gallbladder Empyema in a patient with Situs Inversus, Levocardia and Morbid Obesity: a case report. Brazilian Journal of Case Reports. 2021 Jul-Sep;01(3):155161. 